PipPard, J. \& Ellam, L. (1981) Electroconvulsive Therapy in Great Britain, 1980. London: Gaskell.

S. M. BENBOW

York House

Manchester Royal Infirmary

Oxford Road

Manchester M13 9BX

\section{Familial delusional disorder linked with dyslexia}

SIR: We wish to report an interesting case of a woman presenting with a 15-year history of jealous delusions. The family history reveals a remarkably high prevalence of similar symptoms in first-degree relatives which appear to be linked with dyslexic symptoms of varying degree.

Case Report: The 40-year-old woman lives with her second husband and two teenage sons from her first marriage. She presented with a parasuicidal act in response to what she saw as conclusive evidence of her husband's behaviour. This, she believed, included him having regular sexual intercourse with her two children and him drugging her coffee so as not to be disturbed. The evidence she has is that her husband and sons often looked tired in the morning, and that they stopped talking and appeared to blush when she entered the room. She admitted that her evidence was weak, but it convinced her fully.

Thorough investigations revealed that these beliefs are of delusional intensity. Previous contact with the psychiatric services was discontinued by her as soon as she was confronted with a diagnosis, and no therapeutic intervention was made.

The family history reveals astonishingly similar beliefs to be held by two out of three of the patient's siblings and her paternal uncle and his son. All these family members showed (unfounded) concern that their spouses or friends were having homosexual affairs on a regular basis. Investigations, litigations, and divorces were common consequences. With the exception of the uncle and cousin, on whom we do not have enough information, all those affected by delusional jealousy seem to suffer from a form of dyslexia as well, with varying degrees of difficulties in spelling, reading or writing. The patient's sons are affected by this.

The patient presented as a warm, intelligent and capable woman, who showed no sign of suspiciousness in the rapport she established with us. We diagnosed a reactive depression oocurring in response to delusional beliefs. The depressive symptoms lifted as soon as she had made up her mind to leave the family. There was no evidence of any other pathological perception, but her jealous beliefs were unshakable. Her cognition was unaffected.

As far as we are aware, this is the only reported family presenting with a combination of dyslexia and delusional disorder. Formal testing and evaluation of the severity of both syndromes, as well as cytogenetic analysis, are pending. De Fries et al (1978) suggested that reading disabilities have a significant genetic aetiology. Zahalkova et al (1972) concluded that dyslexia exhibits autosomal dominant inheritance with reduced penetrance. Smith et al (1983) assigned a gene for specific reading disabilities to chromosome 15.

Kendler et al (1985) concluded that delusional disorders and schizophrenia were two separate disorders with different familial factors apparent. They suggested an increase of schizotypal personality disorders in the first-degree relatives of patients with schizophrenia, but not with delusional disorder. Also, an increase of paranoid personality disorders in the first-degree relatives of patients was found with delusional disorder but not with schizophrenia.

This might be a family with a unique combination of delusional disorders and dyslexia from which we can explore the genetic factors involved in more detail.

De Fries, J. C., Singer, S. M., Foch, T. T., et al (1978) Familial nature of reading disabilities. British Journal of Psychiatry, 132, 361-367.

Kendler, K. S., Masterson, C. C. \& Davis, K. L. (1985) Psychiatric illness in first degree relatives of patients with paranoid psychosis, schizophrenia and medical illness. British Journal of Psychiatry, 147, 524-528.

Smith, S. D., Kimberling, W. J., Pennington, B. F., et al (1983) Specific reading disabilities: identification of an inherited form through linkage analysis. Science, 219, 1345-1347.

Zahalkova, M., Vrzal, V., Kloboukova, E., et al (1972) Genetical investigations in dyslexia. Journal of Medical Genetics, 9, 48-52.

Michael Götz YVONNE EDMONSTONE

The Royal Edinburgh Hospital

Morningside Park

Edinburgh EH10 SHF

\section{Capgras' syndrome in association with lithium toxicity}

SIR: I read with interest Canagasabey \& Katona's report (Journal, December 1991, 159, 879-881) of a case of Capgras' syndrome which they attribute to lithium toxicity. The causal role of lithium toxicity is in doubt, however, because the lithium concentration was only marginally outside the therapeutic range at $1.12 \mathrm{mmol} / \mathrm{l}$, and because another psychotropic agent, the monoamine oxidase inhibitor tranylcypromine, was administered and withdrawn in parallel with lithium. Monoamine oxidase inhibitors have not so far been associated with misidentification syndromes as such, but they are known to cause a variety of mental state disturbances (Reynolds, 1982); florid paranoid psychosis secondary to another monoamine oxidase inhibitor, phenelzine, has been reported (Sheehy \& Maxmen, 1978). 